\title{
Ecological Technology for Decreasing Agricultural Non-point Source Pollution from Drainage Ditch Lihuan Liu ${ }^{1, a}$, Wenping Wang ${ }^{1, b}$, Liu Juan ${ }^{1, c}$
}

\author{
${ }^{1}$ Department of hydraulic engineering, Hunan Polytechnic of Water Resources and Electric Power. \\ Changsha 410131, China \\ aemail: liulihuan1980@163.com, bemail:674826546@qq.com, ${ }^{\mathrm{c} e m a i l: 43427206 @ q q . c o m ~}$
}

Keywords: Drainage ditches; agricultural non-point source pollution; pollution control technology; water environment protection

\begin{abstract}
Agricultural drainage is accounting for the largest to China's River Basin water pollution and agricultural non-point source pollution. The ecological function of drainage ditches is important for reducing the pollution. Through effective interception and conversion to preventing and controlling agricultural non-point source pollution is one of the hot spots in the current research. On the basis of analyzing domestic and foreign technique for controlling pollution, the measures are discussed, including the engineering control drainage measures, the ecological interception buildings, WRSIS system, ecological ditch and biological measures. The mechanism and effect of various techniques are clarified and the development trend is looked forward to, which will provide theoretical basis and technical reference for green, ecological and intelligent agriculture.
\end{abstract}

\section{Introduction}

According to "the first national pollution source census bulletin [1]",TP and TN pollution emissions from agriculture accounted for $38 \%$ and $59 \%$ of the country's total emissions .A large number of nitrogen and phosphorus which is not fully utilized by crops is lost with the withdrawal to surrounding water environment, and make lakes and even oceans rich nutrition. Agricultural non-point source pollution has become an important source of water pollution in China.Ditch is an important part of the farmland system, which has the function of both the channel for water catchment as well as water holding and key place for interception and conversion of agricultural non point source pollutants. Due to slow flow of water ,the channel of the base flow is similar to the function of ecological wetland[2][3].Ditch wetland has a unique plant -sediment-microbial system, which can reduce nitrogen and phosphorus concentrations carried by surface runoff to a certain extent by plant absorption, sediment interception and microbial decomposition, etc. Ditch pollution control is a interception blocking technology after the pollutant leaving the field[4], which strengthen the pollution (mainly nitrogen and phosphorus) purification and depth treatment ,by strengthening ecological transformation and function of the existing ditches and ponds , or by constructing additional ecological engineering to use the physical, chemical and biological combined action. The technology not only can effectively intercept and purify the pollutants of farmland, but also can collect and deal with the surface runoff of rural areas and rural domestic sewage,to achieve the reduction of nitrogen and phosphorus in the pollutant discharge or maximum removal[5]'In this paper the main ditches pollution control technology are analyzed and summarized ,in order to provide a reference for reduce pollutants and manage agricultural drainage ditches, and to promote environmental friendly ecological water conservancy technology and In the prevention and control of agricultural non-point source pollution technology to play a better role in the prevention and control of agricultural non-point source pollution.

\section{Engineering technology}

Through the deployment of water conservancy project and the regulation of hardware facilities the major pollutant emission can be reduced. 


\section{Controlled drainage}

At all levels controlled drainage, technology such as drainage valve, gate is used to adjust drainage amount on all level, control the water level, reduce the disturbance of ditch water, increase field infiltration ,and then reduce the concentration of nitrogen and phosphorus in farmland drainage by the filtration and adsorption of soil[6].Through the small gate drain outlet, the surface runoff is intercepted in the experimental plots, and the controlled drainage is formed .The results show that in the average time nitrogen dioxide concentration from non controlled drainage is higher than controlled drainage average nitrogen dioxide concentration and control displacement was reduced than non controlled drainage;surface controlled drainage can effectively reduce farmland nitrogen emissions, and drain nitrogen concentration from controlled drainage is lower $46.8 \%$ than non controlled drainage facilities [7].Field drainage experiment research shows that comparing the measures of automatically open the gate, geotextile sandbags with non controlled drainage , drainage nitrogen concentrations were reduced by $53.2 \%$, $44 \%$ and $39.1 \%$ of the farmland nitrogen loss [8].

\section{Ecological interception building in ditch}

Agricultural non-point source pollution matter is lost most with rainfall runoff into the water.Before entering the water, through the establishment of biological (ecological) interception system , $\mathrm{N}$ and $\mathrm{P}$ pollutants in diameter water is effectively blocked into the aquatic environment. This is an important technical means of agricultural non-point source pollution control.

Abroad, $\mathrm{N}$ and $\mathrm{P}$ runoff migration is controlled mainly by setting broad biological isolation , such as Canadian "grass -trees filter belt system" can significantly reduce runoff pollutant content.[9]. At home, the ditch interception dam is set up.It can effectively remove nitrogen and phosphorus in farmland drainage through ditches plants absorption and matrix adsorption and plant uptake in the filter box, while regulate the water level in the canal and infiltration using nitrogen and phosphorus in groundwater and soil self purification of degradation[6] [10][11].A kind of ecological interception measure is mainly composed of engineering and plant parts intercept ditch system (trench wall is formed by the honeycomb cement board, which in the cement plate uniform hole to subsequent plant construction) [12], and can slow down the speed of water, promote water carrying sedimentation of particulate matter, is conducive to building a plant on the walls of the trench, and the ditch water stereo type escape nutrient absorption and interception. The system can control of discharge of farmland nutrients, and TN and TP removal rate respectively reached $48.1 \%$ and $40.2 \%$.

Another relevant technology for ditch ecological interception is called interception box. In the box the matrix is filled which has the adsorption function to the nutrients in the water body. The substrate and the plants which grow on it together form a complete function of the small unit, which is helpful for the channel to intercept the water and reduce the slow speed.The filling medium of ecological interception dam can be slag and sediment 。 The research shows that the slag dam can not only retain the pollutants, but also effectively prolong the hydraulic retention time, and it is a better choice for the drainage ditch to lay the matrix dam[13].

In addition, the use of different slope protection techniques such as ecological concrete, ecological brick, slope protection network and aquatic plant compound, can protect slope protection, conduce to plant growth and improve ditch ecosystem.

\section{WRSIS system}

WRSIS system was proposed by researchers from Ohio State University in 1990s. It is a comprehensive management system mainly by water conservancy technology, which is used to control, reduce and even solve the problem of farmland non-point source pollution and water and soil environment conservation.System working principle is:Field ditches and pipes collect farmland drainage and surface runoff, and transport it to the wetland; In constructed wetland soil adsorption, plant absorption, biodegradation and so on can reduce nitrogen and phosphorus content in farmland drainage;t water in the wetland is purified and then transported to the reservoir storage; when irrigation is needed, irrigation facilities will supply water to the field.Application results show that the system has the function of reducing the pollution of farmland, improving the irrigation 
guarantee rate and improving the grain yield.At the same time, the increase of the wetland area in the farmland ecosystem is rich in biodiversity,which is conducive to the protection and restoration of farmland ecosystem[14]。

In the demonstration area in Nanjing County of Chun East irrigation project,Li Linna and other specificly improved the United States WRSIS system of wetland subsystem according to the concept of WRSIS system and the problems existing in agricultural production and the current situation of agricultural non-point source pollution in China.They set up an ecological floating bed in front of the constructed wetland, and analyzed the reduction effect of the improved wetland system. Research results show that, the removal effect in dry conditions of pollutants is very significant,TP concentration and total nitrogen concentration decreased by $84.1 \%$ and $88.7 \%$ respectively, total phosphorus and dissolved total phosphorus concentration decreased by $75 \%$ and $75.1 \%$ respectively,and the improvement of WRSIS system is very significant to the purification of paddy field[15].

Combined with the actual situation of irrigation and drainage system in our country,Yan Hong and other reformed the WRSIS system.Control drainage pipe was changed to "ditch drainage".They carried out the experimental research in Momoge region in Jilin Province.Results show that the removal rate of nitrogen and phosphorus in the paddy fields returned to more than 25\%. The improved WRSIS system is a very effective way to control non-point source pollution in rice area[16].

The field experiment was carried out in the WRSIS system of Gaochun County, Jiangsu Province, and nitrogen dynamic change characteristics was analyzed of paddy field surface water and underground drainage under different nitrogen application rates.Results show that: the nitrogen concentration in the surface water and underground drainage increased with the increase of the amount of fertilizer;Fertilization $7 d$ is a critical period to prevent a large number of nitrogen loss, the controlled drainage is needed; at the same time, reducing the amount of nitrogen fertilizer can significantly reduce the loss of surface and underground leakage[17].

Xiaohou Shao et al proposed that it is needed to study the applicability of WRSIS system according to different regional climate, terrain, human characteristics, and the type and extent of surface source pollution because our country has a vast territory; it is also needed to investigate the existing natural wetland resources in China's rice irrigation area;make full use of existing natural wetland resources and ditches ponds facilities, and carries on the optimization;reduce infrastructure investment and occupation of cultivated land resources.At the same time, it can reduce the total amount of agricultural non-point source pollution control parameters, digital, combined with agricultural non-point source water pollution calculation model and information management tools, and establish suitable WRSIS systems engineering in different regions [18].

\section{Ecological ditch system}

According to foreign research reports, ecological ditch is "the best management practices(BMPs)" in agricultural non-point source pollution control[19].Building the ecological ditch is the construction of different ecological ditches and management types, mainly according to the actual situation of embankment, species distribution and two regional economic conditions, as well as the different embankment model, vegetation planting density and species distribution, so that the ditch can intercept non-point source pollution[20].The ecological ditch is composed of farmland drainage ditch and the plants which are planted in the field. Through the ditches to intercept the runoff and sediment, plant retention and absorption of nitrogen and phosphorus, the function of ecological interception of nitrogen and phosphorus is realized[21].In recent years, the research on water purification and agricultural non point source pollution control has been developed by using ecological ditch[22].Related studies showed that the removal rate of nitrogen and phosphorus pollution in agricultural non-point source reached $48 \% \sim 64 \%$ and $41 \% \sim$ $70 \%$.Aquatic plants in a ditch in nitrogen and phosphorus removal plays a important role, in addition to plant uptake of nitrogen in water or sediment, phosphorus, the plant can also extend the 
water residence time in the ditches and microorganisms provide a favourable environment for the growth of other .

In the study of ecological ditch on the effect of water purification process, the impact of pollutants on the ecological ditches and concrete ditches and natural soil ditches were studied. In recent years, screening and ditches of aquatic plants on $\mathrm{N}$ and $\mathrm{P}$ of the interception effect of is in the unfolded[23].

Due to their growth cycle, ditches plants adsorption speed is slow on nitrogen and phosphorus, the absorption of nitrogen is sealed only in the growth period, phosphorus, and in winter nitrogen and phosphorus is released again because of plant decomposition. Therefore ditch plant growth to senescence period, plants decay decomposition in vivo absorption of phosphorus and re released if not timely harvest, which cause secondary pollution. Studies have shown that plant cutting management can directly transfer the nutrients from the ditch, and also improve the removal efficiency of nitrogen and phosphorus in ditch sediments and water .

In a limited number of natural plants , the adsorption capacity of phosphorus in plant ditch system is limited. through human configuration planting, especially like economic plants as bamboo, rice, spinach, cowpea, reasonable collocation planting, making full use of the limited space, and increasing the biomass, the phosphorus removal rate can be improved and the general economic income can be increased. Because the wild type plant ditch is of low economic value, people do not want to take the initiative to harvest. If the economic plants such as wild rice (Zizania latifolia)are planted, it can attract people to regularly harvest plants and then effectively prevent and control the second plant phosphorus pollution.

\section{Biological measures}

It can promote the removal of nitrogen and phosphorus in water to put some chemicals or exogenous microorganisms into the ditch water, such as adding a certain amount of alum and $\mathrm{FeCl} 3$ to the ditch water body, will make the phosphorus purification rate significantly increased. Adding exogenous microorganisms can also increase phosphorus removal effect in ditch system .Exogenous microbes can increase the microbial population and microbial population ,though which microbial degradation is enhanced, and indirectly plant absorption is promoted, so the ditch sewage purifying effect is further improved .Xiaofeng Yin et al[24]ecologically transformed the original farmland ditches in the north shore of Dianchi Liang Jia village,The specific measures are: the direction of water flow along the ditch followed by building a grid, sand pool, hydrolysis acidification tank, anaerobic treatment tank, composite medium (gravel, ceramsite, bamboo charcoal) intercept section of sewage purification unit. The results showed that: the average concentration reduction rate of TN, TP and COD are 70.3\%, 66.6\%, 73.7\% if adding microbial ecological ditch; without adding microbial ecological ditch was $48.3 \%, 60.6 \%$, 58\%, while the traditional canal is $30.1 \%, 23.8 \%, 18.4 \%$. Such farmland ecological ditch not only sewage purification effect is remarkable, but also land saving,and has application and promotion value. Recyclable nitrogen, phosphorus adsorption material was cast in the drainage ditch, we can also received good results.

EM technology can also be used in ditch sewage treatment[25][26].Put EM fermentation liquid, EM Fermented Rice Bran into the mud,and make it as big as a tennis ball ,then place it in fermentation, until its surface is covered with white mycelium, then devote it into a polluted ditches, rivers and ponds every two month launch, and EM fermentation liquid used together, which can achieve better treatment effect. EM fermentation liquid flows with water, and all the place connected waterways can get EM fermentation liquid and was purified. Purification of EM fermentation sludge is stationed in the dumplings in the sludge on the site as EM nutrient medium, constantly releasing EM bacterium, which can quickly remove the odor and sewage sludge. The test results showed that the EM bacterium put into the water has obvious effect on reducing water chlorophyll, suspended solid sand organic pollution index , improving dissolved oxygen, transparency and bactericidal deodorant, and has certain removal effect of nitrogen and phosphorus 
removal. In addition, the safety monitoring of EM and the water body results show that there is no negative impact.

\section{Summary and Outlook}

At present, the pollutant emission reduction mechanism has been more clearly in the farmland drainage ditch system , and related control measures also gradually enriched. With the deepening of research and the diversification of technology, engineering measures, ditches ecosystem and biological measures will be combined to form whole-process pollutant reduction system, which will be one of the future direction of agricultural soil and water environment protection. Now the scholars begin to pay attention to upper water --sediment ecosystem, in which sediment is the substrate for the growth of aquatic plants and the reproduction of the benthic animals; at the same time, the sediment is also a stable place for accumulation and accumulation of pollutants. Many scholars began to study the combined effects of aquatic plants and sediment on the pollutants, and actively study the mechanism and effect of using the system to cut emissions, which provide a new way to improve the construction of ecological ditch. In addition, in order to better reduce and control agricultural non-point source pollution, improving the management of farmland drainage ditches is necessary.

\section{Acknowledgements}

The research was sponsored by the Hunan Provincial Department of education project (Project No. 2016C78596) and the open fund of Key Laboratory of southern area of efficient irrigation drainage and agricultural soil and water environment of Ministry of Education(Project No. E2016001)

\section{References}

[1] Environmental Protection Department of the people's Republic of China, the people's Republic of China National Bureau of statistics, Ministry of agriculture of the people's Republic of China. The first national pollution source census bulletin [EB / OL]. / content ['s] http: / /www. Gov. cn/jrzg/2010-02 / Content_1532174. HTM.Needelman B a, Kleinman P J A, strock J S, et al. Improved management of agricultural drainage ditches for water quality protection: an overview [J]. Journal of soil and water conservation, 2007,62 (4),

[2] Needelman B a, Kleinman P J A, strock J S, et al. Improved management of agricultural drainage ditches for water quality protection: an overview [J]. Journal of soil and water conservation, 2007,62 (4),

[3] Bennett e r, Moore M T, Cooper C M, et al. Vegetated agricultural drainage ditches for the mitigation of pyrethroid-associated runoff [J]. Environmental toxicology and chemistry, 2005,24 (9): 2121-2127.

[4] Lingjiang Cui, Guangbai Cui. Wetlands on agricultural non-point source pollution removal effect [J]. Agro environmental protection, 2002,21 (5)

[5] Yang Lin-zhang, Wieman, retrival. The rural non-point source pollution control "4R" theory and engineering practice overall train of thought and "4R" governance technology [J]. Journal of agro environment science, thewastewater (1): 1-8.

[6] Zhanyu Zhang, Lil Kongi, Xia. The mechanism and control of non-point source nitrogen in drainage ditches in irrigation districts. 2009, (7): 48-51.

[7] Guoxi Yin , Zhanyu Zhang, Xiangping Guo , et al. Experimental study on the effect of surface controlled drainage on nitrogen concentration and emission. Journal of Hohai University (NATURAL SCIENCE EDITION), 2006, 34 (1): 21- 23 
[8] Guoxi Yin , Zhanyu Zhang, et al. Study on the field surface control drainage measures for reducing nitrogen loss in the field. Journal of hydraulic engineering, 2006, 37 (8): 926- 931

[9] Duchemin, Hogue R. reduction in agricultural non-point source pollution in the first year following establishment of an integrated grass/tree filter strip system in southern Quebec (Canada) [J]. Agriculture, Ecosystems \& environment, 2009

[10] Wang Yan, Jianguo Wang, Li Wei, et al. Comparison of nitrogen and phosphorus interception effects of three types of farmland drainage ditches. Soil, 2009, 41 (6): 902-906.

[11] Shunan Zhang, Zhaoyue Jia , Runlin Xiao , et al. Study on the removal mechanism of nitrogen and phosphorus in farmland drainage by ecological ditches. Journal of ecology and rural environment, 2010, 26 (6): 586-590.

[12] Lin-zhang Yang , Xiao-ping Zhou , Wang Jian-guo, et al. Ecological interception ditch system for farmland non-point source pollution control and its effects. Journal of ecology, 2005, 24 (11): 1371-1374.

[13] Zhang Yan.Removal effect of nitrogen and phosphorus by farmland drainage ditch and management measures,2013.

[14] Xiaohou Shao , Xu Zheng, Junyi Tan . Agricultural water and soil environment engineering M. Nanjing: Hohai University press, 2011

[15] Nali Lin , Xiaohou Shao , Li Ling-jun,. Improvement of Nanjing Chun Irrigation District East WRSIS wetland subsystems and anti pollution effect of. Chinese Society for Environmental Sciences Conference papers set [J]. 2011435-438

[16] Yan Hong, Guangmao Shan. Back water pollution treatment method of - wrsis technology introduction and improvement [J]. Journal of Changchun University, 2012, 22 (6): 698-700.

[17] Wen Tao, Xiao-hou Shao , Li Yuan-yuan, et al. The dynamic variation characteristics of nitrogen in paddy field surface water and subsurface drainage in WRSIS system (J). Water resources protection, 2012, 28 (4): 33-37.

[18] Xiao-hou Shao, Xuhui Ji , Xiu-jun Hu , et al. Application of WRSIS system in agricultural non-point source pollution control of rice irrigation area in South China (J). Jiangsu Agricultural Sciences, 2013, 41 (4): 291-293. ecological ditch section Cooper C M [19] M T Moore Bennett ER et al.Innovative uses of vegetated drainage ditches for reducing agricultural runoff J.Water Science and Technology 2004,49 (3): 117-123.

[20] Yingying Fan , Liu Yong, Huaicheng Guo , et al. Study on the protection of the ditches in the lake region based on landscape ecology. Journal of Applied Ecology, 2005, 16 (3): 485 - 481

[21] Ozaki Y. Removal of $\mathrm{N}$ and $\mathrm{P}$ eutrophic from water pond by using plant bed filter ditches planted with crops and flowers[J]. Plant and Soil Sciences 2006, 92: 956 - 957

[22] Hongdeng Xu , BeiDou Xi , Jinggang Wang , et al. Nitrogen and phosphorus removal effect of aquatic plants on farmland drainage ditch (J). Environmental science research, 2007,20 (2): 84-88.

[23] Hong Bing ecological ditch aquatic plants on nitrogen and phosphorus in agricultural non-point source pollution interception effect of [D]. PhD thesis: 2012.

[24] Xiaofeng Yin , Zhengyi Hu , Lixiang Zhou , et al. Study on the construction and purification effect of farmland ecological ditch on the north shore of Dianchi (J). Anhui Agricultural Sciences, 2008, 22 (4): 291-293.

[25] Xiao Hou Shao , Xu Zheng, Junyi Tan . Agricultural water and soil environmental engineering [M]. Nanjing: Hohai University press, 2011

[26] Lihuan Liu , Wen-ping Wang. Prospect of Application of EM Technology in the Water Ditch of Paddy Field[J].Environment,Energy and Biotechnology V ,2016, 93(1): 82-86. 